\title{
Case Report \\ Chest Pain and Costochondritis Associated with Vitamin D Deficiency: A Report of Two Cases
}

\author{
Robert C. Oh and Jeremy D. Johnson \\ Department of Family Medicine, Tripler Army Medical Center, Honolulu, HI 96859, USA \\ Correspondence should be addressed to Robert C. Oh, roboh98@gmail.com \\ Received 5 February 2012; Accepted 4 March 2012 \\ Academic Editor: Mohamud Daya
}

Copyright (C) 2012 R. C. Oh and J. D. Johnson. This is an open access article distributed under the Creative Commons Attribution License, which permits unrestricted use, distribution, and reproduction in any medium, provided the original work is properly cited.

\begin{abstract}
Vitamin D is integral for bone health, and severe deficiency can cause rickets in children and osteomalacia in adults. Although osteomalacia can cause severe generalized bone pain, there are only a few case reports of chest pain associated with vitamin D deficiency. We describe 2 patients with chest pain that were initially worked up for cardiac etiologies but were eventually diagnosed with costochondritis and vitamin D deficiency. Vitamin D deficiency is known to cause hypertrophic costochondral junctions in children ("rachitic rosaries") and sternal pain with adults diagnosed with osteomalacia. We propose that vitamin D deficiency may be related to the chest pain associated with costochondritis. In patients diagnosed with costochondritis, physicians should consider testing and treating for vitamin D deficiency.
\end{abstract}

\section{Introduction}

Chest pain is a leading cause of ambulatory visits and accounts for over 6 million emergency room visits in the United States [1]. After serious cardiopulmonary conditions are considered, musculoskeletal causes of chest pain, including costochondritis, are commonly attributed to the final diagnosis $[2,3]$. Costochondritis is not clearly understood, but may be related to inflammation of the costochondral junctions associated with illness, coughing, or trauma [3]. Although there are a few reports of osteomalacia and vitamin D deficiency associated with chest pain [4-6], we are not aware of any literature reports of costochondritis associated with vitamin $\mathrm{D}$ deficiency. This paper describes two cases of patients with chest pain, eventually diagnosed with costochondritis and vitamin D deficiency.

\section{Cases}

Case 1. A 35-year-old white female presented to the family medicine clinic in Hawaii with complaints of chronic chest pain for the last 3 years. She recently moved from Northern Virginia to Hawaii. Chart review was notable for a negative cardiac workup, including a treadmill stress test, and echocardiogram. Over the last 3 years, the diagnoses of her chest pain included anxiety, esophageal reflux, and costochondritis. In Hawaii, her exam was remarkable only for tenderness to palpation over the left and right costochondral junctions. Since she reported very little milk intake or sun exposure, a serum 25-OH Vitamin D (25-OHD) level was obtained and returned at $42 \mathrm{nmol} / \mathrm{L}(17 \mathrm{ng} / \mathrm{mL})$, consistent with deficiency. She was started on Vitamin D, 1000 international units (IU) daily. On 3-month followup, her repeat serum $25-\mathrm{OHD}$ was $72 \mathrm{nmol} / \mathrm{L}(29 \mathrm{ng} / \mathrm{mL})$ and she had complete resolution of her chest pain.

Case 2. A 42-year-old Asian female with historcarotid Doppley of hypertension and hyperlipidemia presented to a Hawaii emergency department with complaints of substernal chest pain. She was admitted to the hospital for a ruleout myocardial infarction protocol. In the hospital, she was found to have marked tenderness along the left costochondral junction. She did not routinely drink milk and despite living in Hawaii, she reported little sun exposure due to her work hours. After ruling out for myocardial infarction, she was discharged with followup for a treadmill stress test, which was normal. Prior to her discharge, a serum 25OHD level was drawn to rule out vitamin D deficiency. 
On followup, her vitamin $\mathrm{D}$ level returned $27 \mathrm{nmol} / \mathrm{L}$ $(11 \mathrm{ng} / \mathrm{mL})$ and she continued to report chest pains. She was started on oral Vitamin $\mathrm{D}_{2} 50,000$ IU once a week for 8 weeks and maintained on 1,000 IU a day thereafter. Repeat 25-OHD level 2 months later was $82 \mathrm{nmol} / \mathrm{L}(33 \mathrm{ng} / \mathrm{mL})$. Her chest pain resolved with treatment.

\section{Discussion}

In this paper, both patients had extensive workups done with concern for cardiac disorders but were eventually diagnosed with costochondritis and vitamin D deficiency. We hypothesize that these patients' costochondritis may have been related to vitamin D deficiency. Vitamin D is integral for bone health, and serum 25-OH vitamin D (25-OHD) is predictive for body stores of vitamin D [7-9]. While there is controversy over what defines deficient or optimal serum levels of 25-OHD, levels less than $50 \mathrm{nmol} / \mathrm{L}(20 \mathrm{ng} / \mathrm{mL})$ lead to increase in bone turnover markers and increase in parathyroid hormone (PTH) [10]. Another study found that defective bone mineralization was evident in patients with serum 25-OHD less than $75 \mathrm{nmol} / \mathrm{L}(30 \mathrm{ng} / \mathrm{mL})$ but none above that threshold [11]. The recent Institute of Medicine report found evidence that a serum 25-OHD level above $50 \mathrm{nmol} / \mathrm{L}(20 \mathrm{ng} / \mathrm{mL})$ is generally sufficient for bone health for $97.5 \%$ of the population. Hence, a $25-\mathrm{OHD}$ level less than $50 \mathrm{nmol} / \mathrm{L}(20 \mathrm{ng} / \mathrm{mL})$ is generally considered consistent with vitamin D deficiency $[7,8]$. Severe vitamin D deficiency, defined as a $25-\mathrm{OHD}$ less than $25 \mathrm{nmol} / \mathrm{L}(10 \mathrm{ng} / \mathrm{mL})$, can cause rickets in children and osteomalacia in adults [12]. Rickets classically causes "bow legs" or "knock-knees" due to disordered growth along weight-bearing bone. "Rachitic rosaries" describes hypertrophied costochondral junctions in relation to defective mineralization $[13,14]$. Osteomalacia, the adult version of rickets, can cause diffuse bone pain. Tenderness to the anterior tibia, sternum, and costochondral joints can indicate osteomalacia and vitamin $\mathrm{D}$ deficiency $[14,15]$. Although bone biopsy is the gold standard for osteomalacia, it is not generally practiced. Bone pain and vitamin D levels less than $25 \mathrm{nmol} / \mathrm{L}(10 \mathrm{ng} / \mathrm{mL})$ are often sufficient for the clinical diagnosis of osteomalacia.

Although both patients did not have had levels less than $25 \mathrm{nmol} / \mathrm{L}(10 \mathrm{ng} / \mathrm{mL})$ to suggest osteomalacia, we theorize that milder forms of vitamin D deficiency can cause a spectrum of pain along the sternum and costochondral junctions similar to patients with rickets and osteomalacia. Costochondritis continues to be a poorly defined entity but may represent a milder, earlier form of osteomalacia associated with higher serum 25-OHD levels. Importantly, osteomalacia and vitamin D deficiency may not be considered when a patient presents with complaints consistent with costochondritis, as testing for vitamin D deficiency in these patients has not been reported, nor is it routine.

A review of the literature revealed no reported cases of costochondritis associated with vitamin D deficiency, and only a few case reports of chest pain associated with vitamin $\mathrm{D}$ deficiency. One case described chronic chest and leg pain of 2 years duration in a 34-year-old female [4]. After two years of conservative treatment with anti-inflammatory medications, she was eventually diagnosed with osteomalacia associated with aluminum-containing antacid use. Aluminum containing antacids may cause osteomalacia by binding to phosphate, causing a negative phosphate balance and eventual disordered bone growth. However, there was no serum 25-OH vitamin D (25-OHD) level measured to support the diagnosis of osteomalacia. She improved with vitamin D supplementation and decreased antacid use. Another case reported a 37-year-old Indian living in Germany who was subsequently diagnosed with vitamin D deficiency and osteomalacia. Chest pain was the only presenting symptom. His 25-OHD level was undetectable. He was started on high-dose vitamin $\mathrm{D}$ and then maintenance vitamin $\mathrm{D}$ with resolution of his chest pain [5]. Lastly, a 21-year-old Turkish female living in Germany presented with left-sided chest pain with unremarkable electrocardiogram, troponin and d-dimer [6]. Her 25-OHD level was $9 \mathrm{nmol} / \mathrm{L}(4 \mathrm{ng} / \mathrm{mL})$, and she was diagnosed with osteomalacia causing her chest pain. Treatment with vitamin D, calcium, and calcitonin resolved her symptoms in two months. These case reports are suggestive of osteomalacia and severe vitamin D deficiency as the cause of chest pains. It is possible that the spectrum of bone pain, including costochondritis, may be correlated to the degree of vitamin D deficiency.

In our paper, both patients were at significant risk for vitamin D deficiency despite living in an area with abundant sunshine. Vitamin D can only be obtained through ultraviolet light exposure, vitamin-D-rich foods, and supplementation. Both patients reported little to no milk intake, no other vitamin supplementation, and little sun exposure, putting them at high risk for deficiency. The IOM recently increased the recommended daily allowance (RDA) of vitamin D for adults from $400 \mathrm{IU}$ to a minimum of $600 \mathrm{IU}$ in order to maintain 25-OHD levels above $50 \mathrm{nmol} / \mathrm{L}(20 \mathrm{ng} / \mathrm{mL})$ for $97.5 \%$ of the population [7]. However, other expert recommendations have suggested much higher levels of vitamin $\mathrm{D}$, ranging from 400 to $2000 \mathrm{IU}$ daily to maintain adequate serum 25-OHD; depending on risk factors present $[8,9]$. Sun exposure can provide the most efficient means of maintaining vitamin D stores; however, dark-skinned individuals absorb less ultraviolet radiation from sunlight and thus convert less 7-dehydrocholesterol into vitamin D. People living at higher latitudes are at increased risk for deficiency, but studies show that even in areas with adequate sunshine, vitamin D deficiency can be highly prevalent [16, 17].

Our paper has clear limitations. With prevalence of vitamin $\mathrm{D}$ deficiency reported to be up to $36 \%$ in young adults [12], costochondritis may be merely an unrelated association. However, with treatment of deficiency and normalization of their serum vitamin $\mathrm{D}$, both patients' costochondritis improved, further supporting vitamin D deficiency as a potential cause of their costochondritis. The improvement of symptoms may also be attributed to selflimited costochondritis rather than the vitamin D supplementation. However, it is notable that once adequate treatment was initiated, no further cases of chest pains have been reported-including the patient who had 3 years of chronic chest pain. This further strengthens our hypothesis 
that vitamin D deficiency may be a cause of costochondritis. We recommend further prospective studies, specifically in primary care, to help elucidate the association of vitamin D deficiency and costochondritis.

\section{Conclusion}

In patients with costochondritis, or bony sternal pain, physicians should consider vitamin D deficiency and osteomalacia and elicit any risk factors for deficiency. Patients with costochondritis who are at risk for vitamin $\mathrm{D}$ deficiency should be tested with a serum 25-OHD level and treated if found to be vitamin D deficient. Studies looking further at the association of costochondritis and vitamin D deficiency are warranted.

\section{Conflict of Interests}

The authors declare no conflict of interests.

\section{Disclaimer}

The views expressed in this manuscript are those of the authors and do not reflect the official policy or position of the Department of the Army, Department of Defense, or the U.S. Government.

\section{Disclosure}

This paper was presented as an oral case presentation at the Uniformed Services Academy of Family Physicians Annual Conference, New Orleans, LA, February 2010.

\section{References}

[1] S. R. Pitts, R. W. Niska, J. Xu, and C. W. Burt, "National hospital ambulatory medical care survey: 2006 emergency department summary," National Health Statistics Reports, no. 7, pp. 2-39, 2008.

[2] M. H. Ebell, "Evaluation of chest pain in primary care patients," American Family Physician, vol. 83, no. 5, pp. 603-605, 2011.

[3] A. M. Proulx and T. W. Zryd, "Costochondritis: diagnosis and treatment," American Family Physician, vol. 80, no. 6, pp. 617620, 2009.

[4] A. M. Kaufman, J. A. Abraham, S. V. Kattapuram, and F. J. Hornicek, "Chronic multifocal chest and leg pain in a 34-yearold woman," Clinical Orthopaedics and Related Research, vol. 467, no. 4, pp. 1112-1117, 2009.

[5] M. Schiltknecht and J. Furrer, "Chest pain in a 37-year-old Sikh," Praxis, vol. 91, no. 4, pp. 99-102, 2002.

[6] T. Mosimann and C. Meier, "Left-sided chest pain," Praxis, vol. 92, no. 8, pp. 353-355, 2003.

[7] A. C. Ross, J. E. Manson, S. A. Abrams et al., "The 2011 report on dietary reference intakes for calcium and vitamin D from the Institute of Medicine: what clinicians need to know," The Journal of Clinical Endocrinology \& Metabolism, vol. 96, no. 1, pp. 53-58, 2011.

[8] M. F. Holick, N. C. Binkley, H. A. Bischoff-Ferrari et al., "Evaluation, treatment, and prevention of Vitamin D deficiency: an endocrine society clinical practice guideline," The Journal of Clinical Endocrinology \& Metabolism, vol. 96, no. 7, pp. 19111930, 2011.

[9] D. A. Hanley, A. Cranney, G. Jones, S. J. Whitling, W. D. Leslie, and Guidelines Committee of the Scientific Advisory Council of Osteoporosis Canada, "Vitamin D in adult health and disease: a review and guideline statement from osteoporosis Canada (summary)," Canadian Medical Association Journal, vol. 182, pp. 1315-1319, 2010.

[10] A. Malabanan, I. E. Veronikis, and M. F. Holick, "Redefining vitamin D insufficiency," The Lancet, vol. 351, no. 9105, pp. 805-806, 1998.

[11] M. Priemel, C. von Domarus, T. O. Klatte et al., "Bone mineralization defects and vitamin D deficiency: histomorphometric analysis of iliac crest bone biopsies and circulating 25-hydroxyvitamin D in 675 patients," Journal of Bone and Mineral Research, vol. 25, no. 2, pp. 305-312, 2010.

[12] M. F. Holick, "High prevalence of vitamin D inadequacy and implications for health," Mayo Clinic Proceedings, vol. 81, no. 3, pp. 353-373, 2006.

[13] F. R. Greer and L. Finberg, "Rickets. eMedicine," http://emedicine.medscape.com/article/985510-overview.

[14] M. F. Holick, "Resurrection of vitamin D deficiency and rickets," Journal of Clinical Investigation, vol. 116, no. 8, pp. 2062-2072, 2006.

[15] M. F. Holick, "Medical progress: vitamin D deficiency," The New England Journal of Medicine, vol. 357, no. 3, pp. 266-281, 2007.

[16] E. T. Jacobs, D. S. Alberts, J. A. Foote et al., "Vitamin D insufficiency in southern Arizona," American Journal of Clinical Nutrition, vol. 87, no. 3, pp. 608-613, 2008.

[17] N. Binkley, R. Novotny, D. Krueger et al., "Low vitamin D status despite abundant sun exposure," Journal of Clinical Endocrinology and Metabolism, vol. 92, no. 6, pp. 2130-2135, 2007. 


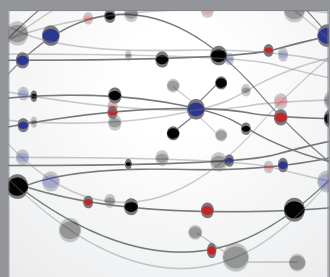

The Scientific World Journal
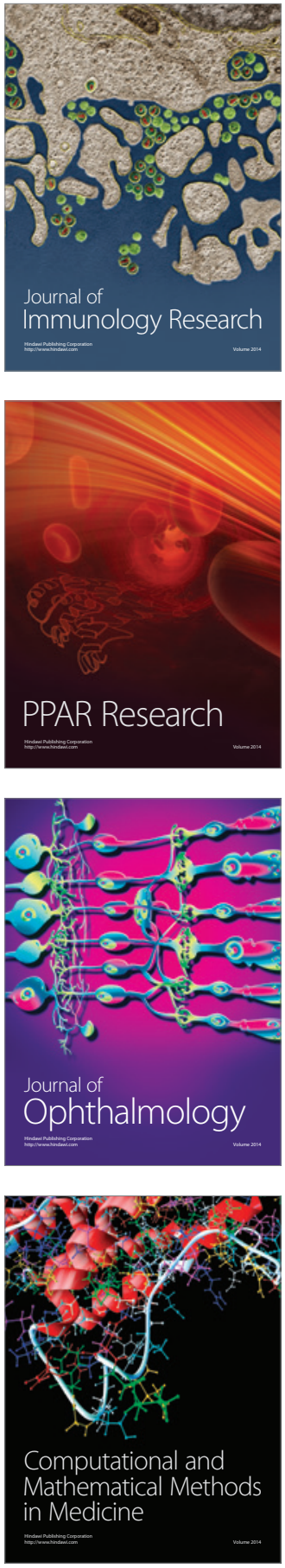

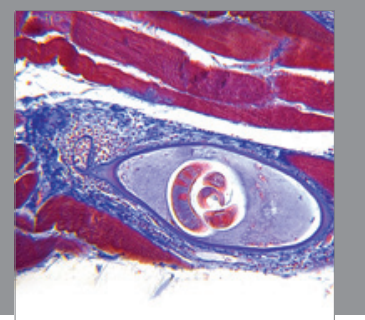

Gastroenterology

Research and Practice
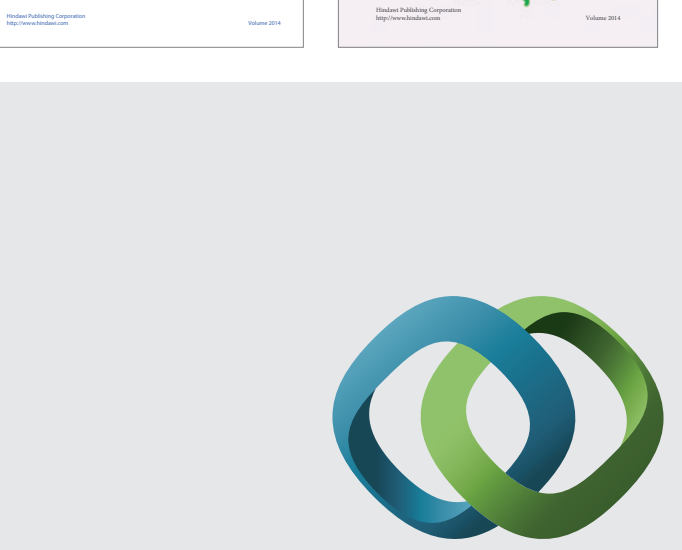

\section{Hindawi}

Submit your manuscripts at

http://www.hindawi.com
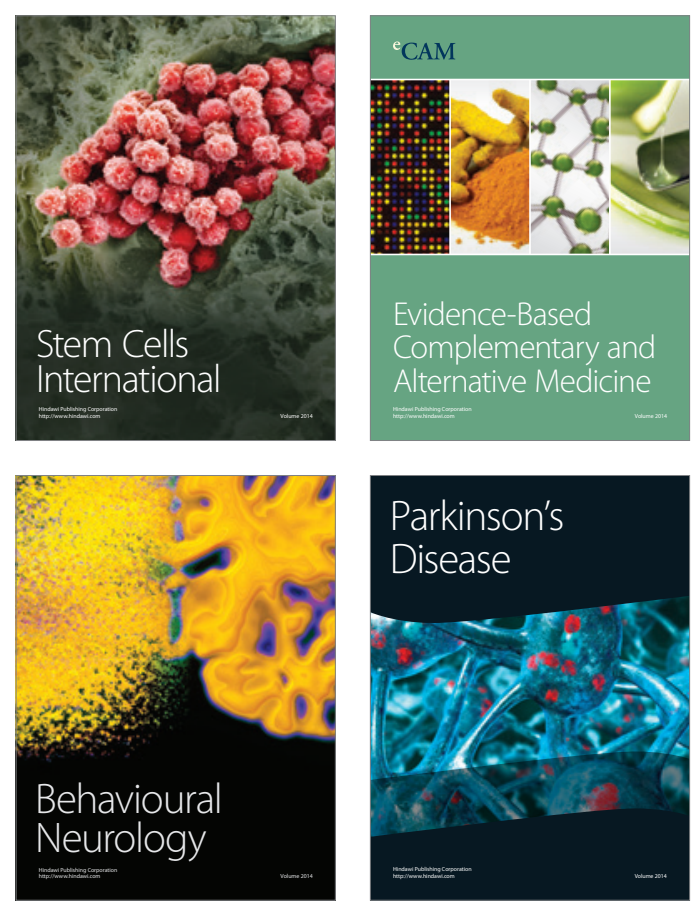

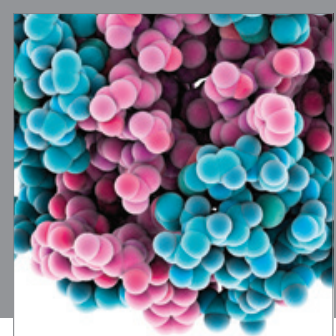

Journal of
Diabetes Research

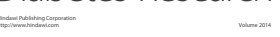

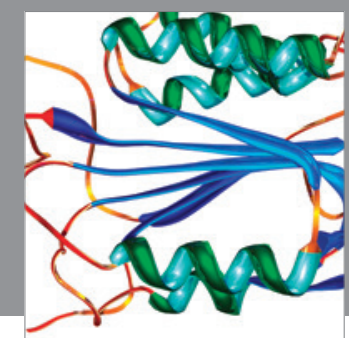

Disease Markers
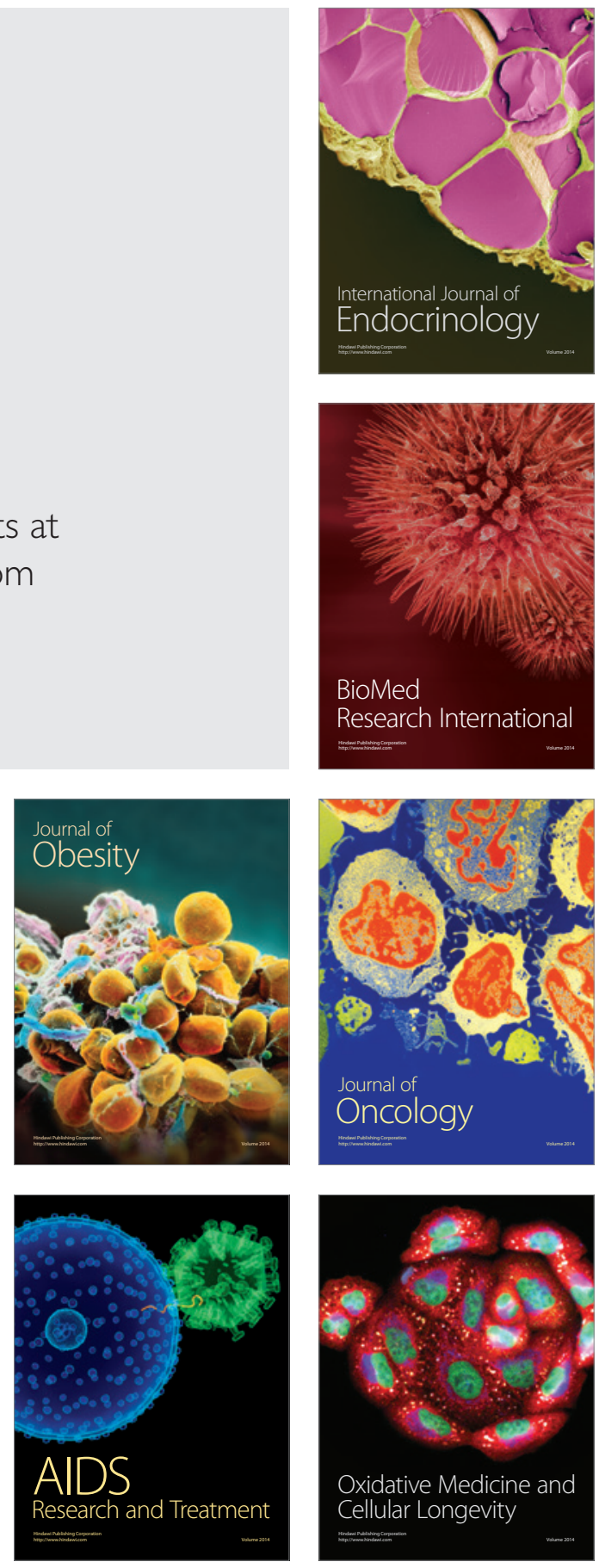